Психодингвистические

аспекты славянской

фразеологии:

“Славофраз-2016" *

\author{
Валерий Михайдович Мокиенко \\ С.-Петербургский государственный \\ университет \\ С.-Петербург, Россия
}

\section{Psycholinguistic Aspects of Slavic Phraseology: "Slavofraz-2016"}

\author{
Valerij M. Mokienko \\ St. Petersburg State University \\ St. Petersburg, Russia
}

Фразеология, как известно, имеет прямое отношение к психологии. Не случайно 3. Фрейд при тестировании своих пациентов обильно использовал фразеологический и паремиологический материал. Слависты-фразеологи давно обратили внимание на эту сторону исследуемых ими языковых единиц и постоянно обращались и обращаются к этой актуальной проблематике. Вот почему, когда Институт славистики университета им. Карла-Франца в австрийском городе Грац (KarlFranzens-Universität Graz) предложил свою научную площадку на тему “Фразеология и (наивная) психология” („Phraseologie und (naive) Psychologie“), на их призыв откликнулось 60 фразеологов из 15 стран.

Не случайно и меткое общее наименование этой конференции, состоявшейся в Граце с 7 по 10 апреля 2016 года, - “Славофраз-2016” (Slavofraz-2016). Ведь именно благодаря инициативе и усилиям профессора Грацкого университета Вольфганга Айсмана в бытность его директором института славистики в 90-е годы прошлого века была создана европейская ассоциация фразеологов - "Еврофраз”, которая сейчас задает тон мировой фразеологии и издает фундаментальные серии трудов по это дисциплине. Проф. В. Айсман привлек к фразеологическим исследованиям своих сотрудников, которым и ранее была не чужда эта проблематика, проф. П. Гржибека, проф. Х. Пфандля, проф. Ханзен-Кокоруш и других, тем самым

* Работа написана при поддержке гранта Российского научного фонда (проект № 17-18-01062). 
создав в Грацском университете признанный европейский центр славистической фразеологии. Им же в 1995 году в Граце была организована международная конференция “Еврофраз-1995”, которая привлекла как патриархов европейской фразеологии (В. Г. Гака, М. М. Копыленко, В. Н. Телия, Е. Эккерта, Й. Матешича и мн. других), так и фразеологическую молодежь, особенно славистическую. “Славофраз-2016” в каком-то смысле стал подведением итогов фразеологических исследований на славянском материале за последнее двадцатилетие. В то же время этот форум стал мощным стимулом развития этой все еще молодой лингвистической дисциплины в европейской славистике.

Сама тематика “Славофраза-2016” подчеркивает отличительную особенность фразеологии от других специализированных отраслей лингвистики. Фразеологизмы и паремии так тесно связаны с этнографией, фольклором, культурологией, социологией и другими экстралингвистическими дисциплинами, что не учитывать их при собственно лингвистическом анализе фактов невозможно. Междисциплинарность фразеологии и была продемонстрирована большинством докладчиков на конференции в Граце.

Инновативным стало само открытие конференции. После приветствия декана проф. Лукаса Maера (Lukas Meyer) и директора института славистики проф. Ренаты Ханзен-Кокоруш (Renate Hansen-Kokoruš) вместо пленарных докладов организаторами конференции (prof. Agnieszka Będkowska-Kopczyk, prof. Heinrich Pfandl) был предложен Открытый круглый стол, на котором были сделаны пятиминутные вводные доклады. Они стали “затравкой” для плодотворных дискуссий, в которые были вовлечены многие участники конференции, а не только приглашенные докладчики. Такое фразеологическое “Talk Show” (кстати, проведенное его инициатором и модератором проф. Петером Гржибеком на английском языке) позволило сразу же расставить доминантные акценты будущих секционных заседаний.

Проф. АГНЕШКА БЕНДКОВСКА-КОПЧИК (AGNIESZKA BĘDKOWSKA-KOPCZYK) предложила для обсуждения многие аспекты лингвистических концепций трактовки эмоций в различной их терминологической огласовке - например, наивная психология (Ю. Д. Апресян), прототипические сценарии (Köveczes и Lakoff), культурные сценарии (A. Wierzbicka). Этот обзор был призван привлечь внимание к культурологической составляющей интерпретации эмоций на фразеологическом материале славянских языков. Проф. Н. БРАГинА предложила для дискуссии дилемму “Наивна ли наивная фразеология?”, продемонстрировав работу подсознания во фразеологическом преломлении. Аналитичность образной семантики фразеологизмов с компонентами душа и сердиз, по ее мнению, по-разному запечатлевается языками разных систем, сохраняя в то же время некоторую универсальную “подсознательность”.

Проф. В. АйсмАн предложил ретроспективную интерпретацию терминов национальная психология (Völkerpsychologie), народная психология (Volkspsychologie), психоанализ (Psychoanalyse) и фразеология (Phraseologie), подчеркнув как общее, так и различное в их взаимодействии. Напомнив о значении, которое 3. Фрейд придавал именно фразеологии в своих анализах подсознательного (где, возможно, переоценивался мифологический универсальный подтекст, не учитывающий конкретные языковые различия), докладчик отметил, что в этом направлении современная фразеология пока почти не продвинулась. 
Проф. В. МокиЕнко предложил для дискуссии несколько дихотомических тезисов: a) Существует ли “ненаивная” (resp. научная) психология, если перед ней не стоит в скобках определение наивная? б) “Наивно” ли или объективно противопоставление внутренней формы словосочетания с его переносным (resp. фразеологическим) значением? в) Возможно ли объективное, “строго научное” разграничение научной этимологии фразеологизмов и наивной (resp. народной, ложной)? г) Каково место “научнойэтимологии” - “наивнойэтимологии” в системе фразеологии?

Проф. А. ШмЕлЕв предложил для обсуждения материал русских метафор движения, обозначающих эмоции и детализированную классификацию эмоциональных состояний. Пространственная метафора эмоции зависит от того, к какому типу эмоций она относится, причем отнесенность эмоции к тому или иному типу может уточняться или модифицироваться посредством определения.

Выступившие в дискуссии развивали идеи, предложенные “затравщиками” Круглого стола, и делились собственным опытом анализа предложенных проблем. В дальнейшем работа была продолжена на секциях, организованных в форме компактных тематических блоков, интенсивно работавших с 8 по 10 апреля. Важно отметить, что доклады на секциях прозвучали практически на всех славянских языках, а также на английском, немецком и французском, что, между прочим, отражает мультилингвальность сотрудников института славистики Грацкого университета.

В секции А были прочитаны доклады, исследующие антропоморфный характер фразеологии разных славянских языков.

В докладе Н. Ф. ВЕнжинович анализировались украинские фразеологические единицы (ФЕ), характеризующие межличностные отношения в виде оппозиций (“умный - глупый”, “чувствительный - бессердечный”, “эмоциональный рациональный”. Фразеология тем самым является языком наивной психологии, отражая психические состояния и процессы, которые переживает человек в разные периоды своей жизни.

Межличностные отношения стали и предметом доклада МАРИи МАЛНАР ЮрИШИч и ПЕтРИНЫ ВУКША НАход (MARIJA MALNAR JuRIŠIĆ, PERINA VuKŠA NAHOD). На материале хорватской диалектной фразеологии проанализированы такие оппозиции, как “согласие - несогласие”, “понимание - непонимание”, “любовь - ненависть”.

Той же теме посвящен и доклад М. Гутовской “Русская и английская фразеологическая психология о межличностных отношениях субъектов спора”. Сопоставление сходств и различий в “оязыковлении” спора стимулирует, по мысли докладчицы, использование фразеологии наивной психологии в обучении иностранным языкам.

Межличностные отношения в инвективном языковом преломлении стали объектом исследования А. АРхАнгЕльской, где анализировались различные магические злопожелательные формулы - проклятия, заклятия и отсылания. Сопоставляя такие формулы в русском, украинском и чешском языках, автор выявляет предметно-тематический код, заложенный в их мифологической семантике.

Тематически близок к этой проблеме доклад BEPы CмOлE (VERA SMOLE) “Cyeверие и колдовство во фраземах восточнодоленского шентруперского диалекта словенского языка (Vraževerje in čarovništvo v frazemih vzhodnodolenjskega šentruperskega 
govora)”. На ярком материале показано “двоеверие”, сохраняемое в течение веков в этом регионе несмотря на то, что языческие представления (например, персонификация нечистой силы) как защита против чумы уже давно исчезла из народной памяти.

Словенские народные издевки и дразнилки стали темой оригинального доклада КАТАРИны ШРИмПФ (KATARINA ŠRIMPF). Этот жанр фольклора распространен не только при оценке соседних народов, но и жителей соседних сел. Он является своебразной языковой провокацией конфликтных межличностных отношений, в основе которой лежит универсальная социальная оппозиция “Свое Чужое”.

Несколько необычным, но в то же время закономерным стало включение в названную серию доклада Х. ВАльTEPA (HARRY WALTER) “Холодная собака и козлиная колбаса в немецком языке и их славянские эквиваленты”. На первый взгляд, его тема далека от психологии межличностных отношений и мифологических представлений. Однако докладчик убедительно доказал, что и здесь, несмотря на “заземленность” характеризуемых соответствующими оборотами артефактов, действует тот же закон “наивной психологии”, что и в оценке духовных явлений - а именно, закон народно-этимологических ассоциаций.

Второй блок докладов, зачитанных в секции А, был сосредоточен преимущественно на роли соматизмов во фразеологии разных языков и ее психологической проекции.

В докладе “Наивная физиология и наивная психология через призму русских идиом” Е. ШМЕЛЕВА и А. ШМЕЛЕВ продемонстрировали лингвоспецифику соматической фразеологии, которая заключается в роли частей тела в человеческой деятельности, в частности, в психической жизни и влиянии на соотношение физиологических и психологических процессов. Особое внимание уделено роли крови, отражаемой в идиоматике.

T. ГухуA (TAMAR GUCHUA) сопоставила структуру соматических фразеологических единиц, выражающих эмоции, в русском и грузинском языках. Несмотря на универсальность языковых образов, заданную экстралингвистическим параметром, фразеологизмы двух языков не тождественны. Автор выделяет три типа фразеологических параллелей: эквивалентные, частично эквивалентные и неэквивалентные. Они анализируются структурно, с помощью символов, квалифицирующих их грамматический статус.

В докладе А. КозЕРЕнко рассмотрены фразеологические единицы, характеризующие всевозможные симптомы эмоций, и сделана попытка определить, какие системы человеческого организма могут быть задействованы и какие нарушения их функционирования фиксируются фразеологией. Автор приводит любопытную статистику: из всех идиом русского языка чуть менее одной десятой составляют идиомы, описывающие эмоции (около 850 из примерно 10000 по данным Тезауруса русской идиоматики, 2007). Они характеризуют такие эмоции и чувства, как радость, горе, страх, недовольство и т. п., а также идиомы, описывающие неопределенное сильное переживание.

Эмоциональное возбуждение в славянских и германских языках стало объектом исследования X. ПФАНдля (HEINRICH PFANDL) и А. БЕНДКОВСКОЙ-КоПчИК 
(AGNIESZKA BĘDKOWSKA-KoPCZYK). Они представили результаты когнитивного анализа фразеологических единиц и словосочетаний, выражающих эмоциональное возбуждение, которые включают лексическую составляющую, связанную с физическим контактом. Они основаны на моделях тактильных-кинестетических действий, которые вызывают определенные телесные ощущения - такие, как боль или чувство прикосновения и под. Данные трех славянских языков (польского, русского и словенского) сопоставляются докладчиками с материалом немецкого и английского языков с попыткой дифференцировать универсальное от национально и культурологически маркированного.

Другие доклады секции А отличались разнообразием.

A. Грняк (ANITA HRNJAK) в докладе с оригинальным названием “И мужчины плачут, разве не так?! (I muškarci plaču, zar ne?)” подвергла анализу стереотипные представления о том, что женщины внешне более эмоциональны, чем мужчины, которые отражены во фразеологии сопоставляемых ею языков (ср. хорв. plakati kao baba, plakati kao žena, - pус. разреветься как баба, хорв. muška suza - pус. скупая мужская слеза или рус. хохотать как русалка, ржать как кобыла, краснеть как красная девиияа и под.).

О психотерапевтическом воздействии смеха и его отражении в чешской и хорватской фразеологии сообщила С. РиБАрова (SlavomiRa RiBARova). Опираясь на обильные материалы Чешского национального корпуса, автор продемонстрировала справедливость представлений о целебном воздействии смеха на психику человека и их универсальность.

Близкую тему в своем докладе “С радостью о словенской фразеологии (Z veseljem po slovenski frazeologiji)” осветили У. ВАЛЕНЧИч APX (URŠKA VALENČıč ARH) и Н. ЯкоП (NATAŠA ЈАКOP). Парадоксально, что словари словенского языка, где слово veselje зафиксировано с XVI в. и активно употребляется, до недавнего времени не зарегистрировали ни одного устойчивого сочетания с этим компонентом. Используя богатые словарные материалы и данные национального корпуса, докладчицы выявили и проиллюстрировали активный коннотативный и фразеологический потенциал этого слова и понятия.

Фразеологический образ страха в языковой картине мира был проанализирован Т. АрХАнгЕльской на материале польского и чешского языков. Докладчицей определены экстралингвистические и лингвистические признаки именования страха как психофизиологического состояния человека и особенности языкового моделирования этого фрагмента аффективной сферы личности. Особое внимание уделено отраженным во фразеологии двух языков традиционным знаниям и представлениям, - особенно фактам наивного мифологического мышления как фрагментам архаичной картины мира.

Концептуализации страха в словенской фразеологии был посвящен доклад И. СтPAMЛИч БреЗНИк (IRENA STRAMLJIČ BREZNIK). ОПределяя страх как одно из неприятных чувств и подчеркивая трудности его собственно языковой дефиниции, докладчица продемонстрировала на богатом материале метафорическую детализацию фразеологических единиц, характеризующих как физиологические, так и психологические признаки соответствующих ощущений.

Концепты “Счастье - Несчастье” в хорватской и немецкой фразеологии были рассмотрены в докладе Ж. МАЦАН (ŽELJKA MACAN) и M. Турк (MARIJA TURK). Bo 
многом ощущения счастливого или несчастливого человека субъективны, что и отражается во фразеологии и иллюстрируется показательными примерами сопоставления двух языков, выявляющих разные типы фразеологических эквивалентов.

Б. БАРчOT (BRANKA BARČOT) интересовало взаимодействие компонентовслов со значением 'ревность' и ‘зависть' с соответствующими фразеологизмами. Сопоставляя материал немецкого, хорватского и русского языков, докладчица выявила семантические и грамматические корреляции таких выражений (blass (gelb, grün) vor Neid sein (werden); platzen vor Neid; vor Neid erblassen; ljubomoran kao pas (pseto); izjedati se od zavisti; pozelenjeti od zavisti; ревность не по разуму; белая зависть; черная зависть; завидовать белой завистью кому; завидовать черной завистью кому и под.).

Концепт “Гнев" во фразеологическом преломлении стал темой доклада M. ОПАШИЧ (MAJA OPAŠIĆ) и Н. СПИЦИЯРИч ПАШКВАН (NINA SPICIJARIĆ PAŠKVAN). Анализ этого концепта был представлен также в сопоставительном ракурсе двух неродственных языков - хорватского и венгерского. Авторы показывают, как психологические и физиологические признаки “Гнева” метафорически мотивируют внутреннюю форму и значение фразем и определяют их различия в сопоставляемых языках.

Этот же концепт стал объектом доклада И. Видович Болт (IVANA Vidović BoLt). Ее оригинальное название - "Кто и почему гневается в хорватской и польской фразеологии? (Tko se i zašto ljuti u hrvatskoj i poljskoj frazeologiji? Frazeodidaktički pristup kongruenciji odabranih frazeoloških jedinica)" - предполагало не только сопоставление “гневной” фразеологии двух языков, но и предлагало анализ культурных моделей, налагающих печать на типы межъязыковой эквивалентности. Описанная автором градация языковых обозначений состояния гнева используется им и в практике преподавания иностранных языков.

Секция В была представлена не меньшим числом докладов и тематически концентрировалась на характеристике ментальных, возрастных и соматических циклов, воплощенных во фразеологии разных языков.

Само название доклада Т. Бочиной “Глупым счастье от безумья, умным горе от ума” свидетельствует, что речь идет о древнейшей семиотической оппозиции. Автор продемонстрировала особенности взаимодействия гедонистических и интеллектуально-познавательных ценностей и антиценностей в русских пословицах и поговорках, выделив различные логемы, основанные на пересечении оппозиции “Ум - Глупость".

На материале словенской паремиологии С. БАБич (SAŠA BABIČ) рассмотрела близкую семиологическую оппозицию - “Умный - глупый”. Пословицы, хранимые в архиве Института словенской этнологии АН Словении, отражают эту оппозицию в русле наивной психологии, концептуализируя стереотипы разного уровня - от объективной оценки этих полюсов ментальности до суеверий и предрассудков.

Оппозиция "Ум" - “Глупость” в словенском языке стала предметом рассмотрения и в докладе М. ЕМЕЦ ТомАЗин (MATEJA JEMEC TOMAZIN). При этом автор подвергает анализу фразеологию в специальных юридических текстах, детально описывая языковые средства, которыми обозначаются полюса этой оппозиции. В профессиональных текстах, по наблюдению исследовательницы, возможны и 
нейтральные обозначения данных ментальных особенностей, в то время как в живой и литературной речи они в основном оценочны.

Оппозиция "Рациональное - иррациональное” стала предметом анализа в докладе А. КжижАновской (ANNA KRZYŻANOWSKA). Эта оппозиция зиждется на противопоставлении человеческого поведения лиц, подверженных или не подверженных эмоциям. Опираясь на материалы польского и французского национальных корпусов, автор сопоставляет фразеологию соответствующих языков и обнаруживает в их системах как общие, так и дифференциальные характеристики.

Концепты “Равнодушие” и “Незаинтересованность” в зеркале хорватской фразеологии стали объектом исследования Ж. Финк (ŽELJKA FINK). Сопоставляя ее с аналогичным материалом других славянских и неславянских языков, автор отмечает эмоциональную насыщенность таких фразеологизмов и в то же время подчеркивает, что сама семантика этих концептов приводит к ситуациям, которые характеризуются более или менее нейтрально. В докладе многоаспектно анализируются около 20 фразем такого типа.

M. БАсич (MARTINA BAŠIĆ) предложила развернутый анализ концепта “Скука” в хорватской (resp. чакавской) речи. По ее мнению, необходимо различать два типа отношений, охватываемых данным концептом. С одной стороны, это эмоциональное состояние, в котором человек чувствует отсутствие интереса к текущей деятельности или чувство пустоты из-за отсутствия интересного содержания или событий. С другой стороны, это характеристика поведения, нарушающего психическое равновесие и провоцирующего скуку. Чакавские идиомы сопоставляются при этом с идиоматикой хорватского литературного языка.

Психологию здравого смысла О. ФЕдосов (OLEg Fedoszov) анализировал на материале русских и чешских идиом со значением '(по своей оплошности или неосведомленности) очутиться в неприятном, неловком или невыгодном положении', которые, в силу своей экспрессивности, образуют активные синонимические ряды. Докладчик ставит и отвечает на несколько вопросов о специфике данной фразеологической номинации для сопоставляемых языков и о связи многообразия таких идиом и разнообразия их внутренних форм с отражением ими национально-культурной специфики. Допускается при этом, что универсальность ситуации делает языковые различия в принципе нерелевантными.

Такие важные свойства человеческого менталитета, как “Память” и “Забывчивость”, стали объектом анализа М. Л. ФАБчич (MELANIJA LARISA FABČIČ). Coпоставляя фразеологию, характеризующую эти свойства в словенском и немецком языках, докладчица приходит к выводу о том, что они концептуализируются исключительно метафорически, причем в русле не только наивной, но и научной психологии, формируя модели мышления.

На материале конкретного анализа польского устойчивого сравнения jak dziecko ‘как ребенок’ в когнитивном ключе, Й. Шершунович (JoANNA SZERSZUNowICZ) предложила несколько замечаний о феномене наивной психологии. Ею был проведен опрос польских респондентов, которые по-разному, но именно в духе наивно-психологических представлений интерпретировали данное выражение.

Проблеме возрастных характеристик человека в русской и чешской фразеологической картинах мира был посвящен доклад Л. СтЕпАновой. Анализ проводится на материале составляемого автором и его коллегами русско-чешско- 
польского идеографического словаря “Человек во фразеологической картине мира”. Докладчица предложила методику выявления сходств и различий в восприятии возраста носителями русского и чешского языков.

Близкая тема раскрывалась в докладе “Жизненный цикл во фразеологии” К. Вельяновской (KATERINA VELJANOVSKA). Различные фазы этого цикла, начиная рождением и детством и кончая старостью, отражены во фразеологии. Их дифференциацию докладчица продемонстрировала на македонском материале, особое внимание уделив идиоме, которая включает весь жизненный цикл - od lulka do groba (dupka) букв. 'от колыбели до могилы'.

В докладе “Концептуализация эмоций в словацкой и сербской фразеологии” C. Паунович Родич (Stefana PAunović Rodić) обратила внимание на тесную связь субъективных реакций человека на внешние и внутренние обстоятельства. Соматические реакции (физиологические процессы, состояние тела и т. д.) находят выражение во фразеологии на уровне интуитивной и научной информации. Тем самым подтверждается влияние культурных факторов на фразеологическую характеристику эмоций.

Взаимосвязь эмоций с физическим состоянием человека стала концептуальной осью доКЛада Б. КОВАЧЕВИч (BARBARA KovAČEVIĆ) и Э. РАМАДАНОВИч (ERMINA RAMADANOVIĆ) “Выражение эмоций в хорватской фразеологии”. Опираясь на естественнонаучные авторитеты, начиная с учения Ч. Дарвина, и современные модели классификации эмоций, докладчица на основе корпуса хорватского языка анализирует соматическую фразеологию, выявляя те обороты, которые имеют эмоциональную мотивацию (например, ljut (bijesan) kao ris (pas), srce je stalo komu <od straha> или srce je sišlo (silazi) u pete komu, srce se steže (steglo, stislo и под.) komu).

“Выражение чувств и эмоций в болгарской фразеологии” - тема доклада Г. ПЕтровой. Исходным моментом здесь стало разграничение понятий “Чувство” и “Эмоция”. Чувство характеризуется как длительное, относительно устойчивое и субъективное отношение к кому-л., чему-л., в то же время эмоция - это кратковременное, интенсивное и ситуативно мотивированное психическое возбуждение. Автор делает попытку показать это кардинальное различие на болгарском фразеологическом материале, сопоставляя его с соответствующими лексемами.

Доклад П. ДроновА (подготовленный в соавторстве с А. Полян) был посвящен идиомам с компонентом зуб. На примере таких оборотов было показано, как этот соматизм связан с мыслительной деятельностью (рус. ни в зуб ногой), эмоциями (рус. скрежет зубовный, иметь зуб на кого, сербск./хорватск. imati zub na koga, англ. gnash one's teeth и т. п.), речевой деятельностью (англ. to lie through one's teeth 'нагло лгать', букв. 'лгать сквозь зубы', ирл. labhairt gan fiacail a chur ann 'грубая речь', букв. 'речь, в которой не найти зубов’). Анализу подверглось варьирование идиом, изменение их значения и возможные контаминации метафорических моделей.

Т. НЕдАшкинА продемонстрировала роль фразеологизмов с компонентами серие и око в наивной картине мира украинцев. Ею проведен психолингвистический анализ 4900 реакций, полученных с помощью свободного ассоциативного эксперимента с 35 стимулами-фразеологизмами с целью реконструкции фрагмента наивной картины мира у носителей украинского языка. 
Те же самые соматизмы в составе немецкой и русской фразеологии стали объектом доклада "Фразеологизмы со словом Auge $(n) /$ глаз (a) в немецком и русском языках как отражение внутреннего мира человека” Л. НЕФЕдовой. Отталкиваясь от латинской пословицы Vultus est index animi (нем. Das Auge ist des Herzens Zeuge, рус. Глаза - зеркало души), докладчица констатирует универсализм фразеологизмов с этими соматизмами, не упуская из виду и национально-специфических характеристик, получивших в них отражение.

Компонент “Глаз” в составе русской фразеологии был проанализирован и Е. СЕливеРстовой в докладе “Фразеологизмы с компонентом глаза как проявление наивной психологии”. Представленные во фразеологии разнообразные характеристики человеческого взгляда связаны со способностью глаз и посредством глаз указывать на физическое и/или душевное состояние личности (хлопать глазами, вытаращить глаза, смотреть во все глаза, глаза на мокром месте), выражать весьма широкий диапазон отношения к присутствующим, к собеседнику (сверлить глазами, глаза прятать). Устойчивые обороты с компонентом глаз, таким образом, указывают на чувства, состояния и отношение.

“Фразеологический портрет души как главного органа психического мира русского человека” - тема доклада И. ВЕпРЕвой, которая перекликалась с проблемами, очерченными в пленарной дискуссионной “затравке” Н. Брагиной.

И. Яндль (INGEBORG JANDL) подвергла анализу антропологическую категорию эмоциональной речи на материале русского дискурса о любви. Интерпретируя избранные литературные тексты и письма с объяснениями в любви, докладчица пытается дефинировать типы дескриптивных отношений между телесным, душевным и пространственным параметрами, характеризуемыми соответствующей идиоматикой.

“Семиотика клише в масс-медиальном дискурсе” - тема доклада Н. ШАРмАновой. Рассматриваются стереотипные комбинации словесных знаков, которые являются материализованным выражением клише сознания. Автор стремится отграничить клише подобного рода от подобных языковых образований. В восприятии содержания информации СМИ языковое сознание рецепиента информации стремится ассоциировать заданные клишированные формы с давно известным содержанием.

Заключительный доклад секции В - "Религиозная деятельность субъекта и ее отражение в языковой картине мира” Т. Ицкович построила на материале русской фразеологии. Удельный вес соответствующих единиц в общей фразеологической системе русского языка весьма велик и имеет тенденцию к расширению.

Третья, общая, секция была посвящена стратегическим проблемам темы, вынесенной в название конференции, - “Фразеология и (наивная) психология”. Ее название было довольно широким, ибо на таких заседаниях объединялись все участники конференции.

И. ШАРонов в докладе “Наименования эмоциональных реакций в русском языке” обобщил достижения теории базовых (универсальных) эмоций и критически оценил их разные классификации. Докладчик выявил наиболее часто встречающиеся в русском языке наименования эмоций на основе анализа двух русских грамматических конструкций, описывающих эмоциональное состояние человека: V от N (gen); V в N (loc). Наиболее частотные коллокации, собранные 
на основе национального корпуса русского языка, позволят, по мнению И. Шаронова, составить список русских номинаций эмоций и коллокаций - стереотипных способов их выражения.

П. Дюрчо (PETER D̃URČO) раскрыл в своем докладе коллокативные отношения эмоциональных существительных в немецком, словацком, русском и других языках. Коллокации, т. е. узуализированные словосочетания, представляют собой гетерогенный набор различных языковых элементов. Автор сосредоточивает свой анализ на комбинаторике “эмоциональных” существительных, образующих коллокации. При этом ставятся следующие вопросы: 1) мотивированы ли коллокации такого рода спецификой одного языка либо диктуются межъязыковыми регулярностями? 2) если в сопоставляемых языках существуют сополагаемые коллокации, то какова их природа в других языках, где имеются параллели и различия, и соответственно - каковы предпочтения комбинаторики “эмоциональных” существительных? 3) можно ли приписывать соположенным эмоциональным коллокациям эквивалентные значения и функции, либо они различаются в зависимости от разных контекстных факторов? Докладчик подчеркивает и значимую роль прагматических факторов.

Девиантные психологические состояния в русских устойчивых сравнениях были рассмотрены в докладе Е. НиколАЕвой. Их многочисленность и разнообразие делают эти единицы маркированными и детализированными обозначениями различных девиантных психологических состояний человека: как бешеный, как сумасшедший, как ненормальный, как полоумный, как невменяемый, как безумный, как обезумевший, как шальной и т. д. Их можно отнести к той же структурно-семантической модели, что и компаративы со сравнительной частью, выраженной лексемами, обозначающими физическое воздействие на человека: как ошпаренный, как угорелый, как настеганный. Анализ словарных дефиниций и контекстов употребления таких оборотов позволяет выявить различия в их семантике и вычленить набор признаков, который в народном сознании связывается с поведением психически больного человека, определить, нарушение каких социально-этических норм являлось девиацией с точки зрения наивной психологии.

Т. ВАлодзинА предложила слушателям этнолингвистический комментарий хтонических образов сферы эмоций в славянских и немецких фразеологизмах. К ним относятся гнев, страх, раздражение, т. е. реальные эмоции, переживания, при мифологизации которых возникает необходимость в их персонификации в образе определенного существа. Восприятие эмоции в субъектных категориях и активное приписывание ей прежде всего зооморфных черт (например, червя) во многом определяет сценарий поведения человека и фразеологическую вербализацию этого поведения. Здесь действует универсальная для человеческого сознания и мифологии оппозиция “Свой - Чужой”.

В рамках этой общей оппозиции рассматривался и словенский материал Э. Кржишник в докладе “Самому себе чужой (Samemu sebi drugi)”. Речь шла о таких оборотах, как biti (ves, čisto) iz sebe ‘быть вне себя’, biti pri sebi ‘быть в себе’, biti poln samega sebe букв. 'быть наполненным самим собой'. Эти фраземы в основном характеризуют исключительно интенсивные эмоции и экстремальные физические и эмоциональные состояния. 
В докладе В. ВАсиЛьЕвой-БЕГУн “Жизнь на эмоциях без чувств?” представлен анализ предложно-падежной формы на эмоцииях, употребляемой в русской современной речи в наречной функции (говорить на эмоциях) или в качестве категории состояния (быть на эмоциях). Данные ресурса Национального корпуса русского языка и актуальные материалы масс-медиа показывают распространение оборота на эмоциях в диффузном значении как с одобрительной, так и с негативной оценкой соответствующего состояния.

Тема доклада Н. Вулович (NATAŠA Vulović) - “Эмоции и психические состояния, выраженные фразеологическими единицами с религиозными компонентами в сербском языке”. Такие лексемы с религиозной семантикой, как душа, Бог̄, Ђаво, чрква, молийва и др. образуют активные ряды фразеологизмов разной

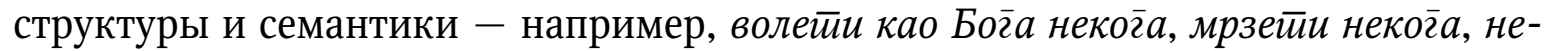

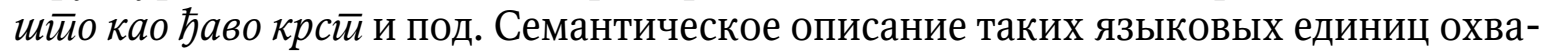
тывает ключевые концепты человеческих эмоций и состояний. Компонентный анализ с историко-этимологическим и лингвокультурологическим подходом позволяет выявить отражение христианского наследия в сербской фразеологии.

Взаимоотношение христианской культуры и фразеологии стало и предметом доклада H. РАЙноховой (NATALJA RAJNOCHOVÁ) "Реминисценция библейских фразеологизмов в наивном сознании современного человека”. Исходя из тезиса о том, что семантика фразеологических единиц далеко не всегда зависит от семантики его компонентов, а обусловливается многими факторами (например, личностной и национальной картиной мира индивида, градацией ценностей определенного социума и т. д.), докладчица анализирует разные типы фразеологизмов библейского происхождения и показывает, как в них проявляется наивная психология говорящих.

Своеобразным итогом конференции стали три доклада общей секции, прозвучавшие в воскресенье, 10-го апреля.

П. ГРжИБек (PETER GRZYBEK) в старую, как античный паремиологический мир, проблему “дефиниции пословицы” влил молодое вино проблематики, заданной организаторами нашей инновативной конференции. Им был поставлен острый вопрос: являются ли известные нам с древнейших времен определения пословицы и поговорки профессиональными (т. е. научно корректными) или же они остаются наивно-психологическими? Не разрешенная со времен Аристотеля, эта проблема продолжает волновать современных фразеологов и паремиологов, рождая бесконечные дискуссии. Докладчик предложил критический обзор многочисленных подходов к этой проблематике и призвал к аналитическому сопоставлению профессиональных и наивно-фольклористических дефиниций пословицы. При этом было отмечено, что к дефиниционной истине наиболее близко подошли исследователи англо-американского, германского, романского и славянского академического (т. е. профессионального) мира.

Диалектический симбиоз научной и окружающей участников конференции реальной действительности воплотился в докладе А. БАРAH (ANNELI BARAN) “Пословицы о погоде как модель народной психологии”. Действительно: апрельская погода, царившая в Граце во время конференции, располагала и к научным заседаниям, и к познавательным прогулкам по этому уютному университетскому городу, одному из центров австрийской славистики. Докладчица показала, как в 
прогностической паремиологии отражаются самые разноречивые факторы предсказания погоды - от сугубо реалистических, навеянных многолетним крестьянским опытом, до заведомо наивных, мифологических, ирреальных. Отмечая определенный универсализм этих пословиц в немецком, русском и эстонском языках, докладчица вместе с тем продемонстрировала их национальную специфику, обусловленную как средством обитания соответствующих народов, так и языковой средой, которой они порождены.

M. МЕTEPЦ (MATEJ METERC) представил в своем докладе результаты собственных психолингвистических разысканий, целью которых было установление известности/неизвестности (resp. употребительности/неупотребительности) словенских пословиц носителями языка. Данные известных словарей докладчик сопоставил с материалами национального корпуса словенского литературного языка, которые затем были проверены путем опроса носителей языка. Оказалось, что в реальном употреблении “нулевых” (т. е. кодифицированных лексикографически) вариантов паремий значительно меньше, чем их вариантов, бытующих в живой речи и достаточно репрезентативно отраженных в корпусе. Такие исследования несомненно станут перспективой дальнейшего изучения и лексикографического описания славянской паремиологии. Тем более что сайт доступен всем, кто такими проблемами заинтересуется: http://www.slavofraz.uni-graz.at/.

Нельзя не отметить образцовую организацию “Славофраза-2016”, научную и подлинно дружелюбную атмосферу его проведения. Поддержку конференции оказали городские власти, о чем свидетельствует и коллегиальный прием его участников бургомистром в старинной Ратуше. Объединительному духу, царившему на конференции, способствовала и познавательная поездка по Штирии, где участники смогли пообщаться с жителями и насладиться незабываемыми пейзажами. Словом, дилемма “научная или наивная психология” фразеологами-славистами как всегда была разрешена диалектично: славянская фразеология и ее носители и исследователи до научного наивны и до наивности научны, что и является неистощимым ресурсом ее национального колорита и языковой экспрессивности.

Acknowledgements

Russian Science Foundation. Project No. 17-18-01062.

проф. Валерий Михайлович Мокиенко, доктор филол. наук

С.-Петербургский государственный университет, филологический факультет, профессор кафедры славянской филологии, председатель фразеологической комиссии

при Международном Комитете славистов

199034 С.-Петербург, Университетская наб., д. 11

Россия/Russia

mokienko40@mail.ru

Received June 27, 2016 